\title{
Impacts of Windfarm Development Activities on Rocky Plateaus - Discussions on Chalkewadi plateau, Dist. Satara, Maharashtra
}

\author{
Manasi Karandikar, Ketaki Ghate, Ketaki Kulkarni
}

Manasi Karandikar, is Co-founder and Managing Partner at oikos for ecological services since 2002. She is also Faculty, Trustee and core team member at Ecological society. She has written articles in magazine and news papers, co-authored a book on Nature conservation, and published databases on Native plants. She has been active member of HLMC, Matheran, 2012-2014. She has worked on various land mapping, planning and development aspects and initiated nature conservation perspective in land development since 2002 through oikos.

Email : manasi@oikos.in

Ketaki Ghate, is Co-founder and Managing Partner at oikos for ecological services since 2002. She is also Faculty, Trustee and core team member at Ecological society. She has been active member of PTA (Pune Tree Authority) and JFM, Pune. Has written articles in magazine and news papers, co-authored a book on Nature conservation, and published data bases on Native plants. She has worked on various biodiversity assessment, land mapping, planning and development aspects and initiated nature conservation perspective in land development since 2002 through oikos.

Ketaki Kulkarni, is Project assistant at oikos for ecological services since Nov 2011, worked on various projects for eco-education, eco-assessment, habitat analysis and mapping. She has been a Spark fellow at BAIF and worked on on-ground restoration of Sacred groves with community participation during 2010-11. She has also worked as a Technical Support in ISSAC (an Environmental Safety and Security firm) during 2009-10.

\begin{abstract}
Rocky plateaus are ecologically very important as they harbor special diversity and are part of catchments of major rivers of Maharashtra. Detailed studies on the components and fragility of rocky plateau ecosystems are sparse. Recently, the instances of these plateaus being subjected to various land use changes without detailed assessments, have affected the balance of the complex ecosystem and the services offered by them. Windfarm development is one major activity on the rocky plateaus for which little data is available on ecosystem level impacts.

Results of the present study describe the Chalkewadi plateau complex, Satara district and impacts on the plateau surface brought about by the development of a high-density windfarm. Broad observations were made on the changing land use, microhabitats and associated vegetation. Manual analysis of Google Earth images of the plateau was done to understand the nature and scale of the ground-level disturbance.

Results show that even though the actual area under windmill establishment is relatively smaller compared to the total plateau area, its environmental footprint is relatively large. The network of temporary and permanent roads, created to erect and operate the windfarm, has dissected the habitat and corridors of wildlife movement. An increase in road kill incidences was observed. Roads have also initiated erosional features all along the plateau surface. Disturbance due to windfarms is widespread on the plateau with the only exception being in the Reserve Forest area and disconnected smaller plateaus.

Our results complement conclusions from other studies regarding negative impacts of windfarms on birds and reptiles. Thus overall impact of windfarms, in terms of habitat destruction is significant and should be studied in depth before establishment of wind farms.

Establishment of windfarms on ecologically sensitive areas should be avoided as far as possible. However, we recommend good ecological management practices that could reduce the impacts, if wind farm establishment is inevitable. The recommendations can be applied to other plateaus in Sahyadri where windfarms are already in place.
\end{abstract}


Keywords : Sahyadri, Northern Western Ghats, Rocky plateaus, Windmills, Windfarm impacts, Area mapping, Ecological management plan

\section{Introduction}

Historically, wind energy was harnessed mainly for sailing ships and for water pumps as a source of mechanical energy. The first windmill used for electricity generation was in July 1887, in Scotland. Since then to the current date, technological advancement has improved the windmills and technology for use in alternate power generation. Today it has gained popularity as clean energy.

India has been active in producing wind energy since 1990s and today is one of the leading manufacturers of wind turbines. The total installed capacity of wind power in India on 31 $1^{\text {st }}$ March 2012 was $17351.60 \mathrm{MW}$ that reportedly saved 89.72 million tones of coal and 118.29 million tones of $\mathrm{CO}_{2}$ emissions. The wind energy generation capacity in India is $49130 \mathrm{MW}$ as per the official estimates of the Indian Wind Atlas, (2010) by the Center for Wind Energy Technology (C-WET). There are many regulatory and policy incentives for wind power like accelerated depreciation, renewable energy certification, direct subsidies, excise duty exemption, and sales tax concession, due to which wind energy farms are becoming popular among industries and wealthy individuals. Even conversion of land under forests has been allowed for installation of wind farms. In Maharashtra, many areas in the Western Ghats section were identified as suitable for windfarm establishment leading to windfarm development on mountain tops.

The Western Ghats is a mountain range traversing Western India from Gujarat to Kerala with north-south length of almost $1600 \mathrm{~km}$. It is separated from the Arabian Sea by the narrow belt of Konkan - Malabar coastal area. In W. Ghats, high elevation, torrential rains, high speed winds, extreme temperatures, humidity and hilly topography give rise to a specialized, sensitive ecosystem with rich biodiversity. It is identified as a global biodiversity hotspot owing to high endemism and high anthropocentric pressures on biodiversity. Northern Western Ghats, known as Sahyadri, are characterized by flat tops and rise to an average elevation of $1000 \mathrm{~m}$, reaching $1400 \mathrm{~m}$ in some areas (e.g. Kalasubai, Mahabaleshwar). The range is mainly composed of basalt, an igneous rock formed due to cooling of Deccan trap lava flows. The Deccan traps are mostly flat, thus giving rise to flat-topped mountain ranges. Erosional forces have worked over millions of years and changed the flat tops to gradual or steep free falls at many places. Many plateaus have weathered to form layers of lateritic soil supporting vigorous growth of woody vegetation, e.g. forests of Bhimashankar and Mahabaleshwar. However, extensive rocky plateaus exist throughout the range.

Watve (2013) has discussed the rocky plateaus as a specialized habitat with endemic biodiversity that were grossly neglected in the past. Studies by Lekhak et al. (2012) and Bhattarai et al. (2012) have given detailed descriptions of microhabitats on rocky plateaus, their associated plant diversity and endemism. Rocky plateaus are subjected to extreme wet and extreme dry conditions in monsoon and in summer respectively. The organisms living on such plateaus have evolved to adjust to these conditions.

'Ecosystem services' rendered by these habitats to

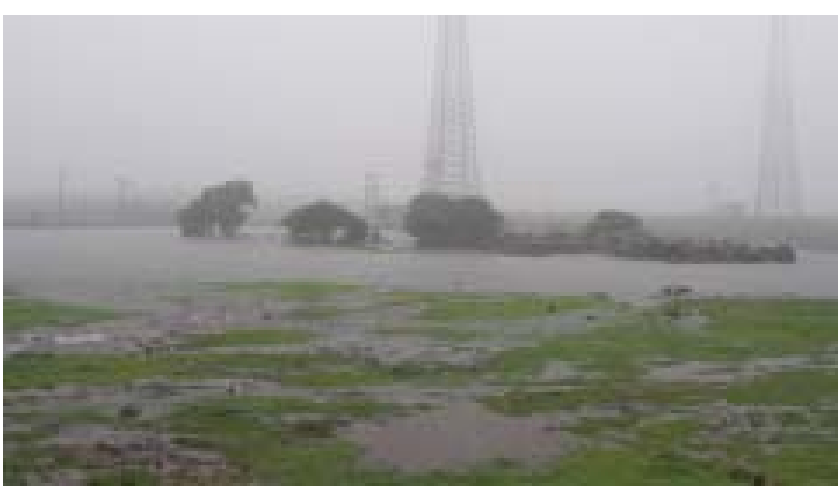

Image 1 and 2 : Images showing plateau in two extreme conditions - summer and monsoon 
immediate local communities have been documented. Buono and Thomas (2013) document the community's dependence on spring water that are recharged by deep soil profiles of these plateaus. This emphasizes the importance of these landscape features as water catchments for local populations. Other major services include mass blooming ephemerals which supports pollinators and nutrient supply to lower areas.

Rocky plateaus were designated as 'wastelands' in Government records. In the Wastelands Atlas of India by the National Remote Sensing Centre and Ministry of operations on the surface of rocky plateau site. We also suggest best practices for reducing the ground level impacts of the windfarms which will help protect the biodiversity during the operations phase.

\section{Methods}

This paper reports studies conducted on Chalkewadi plateau from May 2006 to July 2015. It is an ongoing study and will continue after 2016 as well. There are two aspects of the study, field observations and mapping of land features and changes over time.
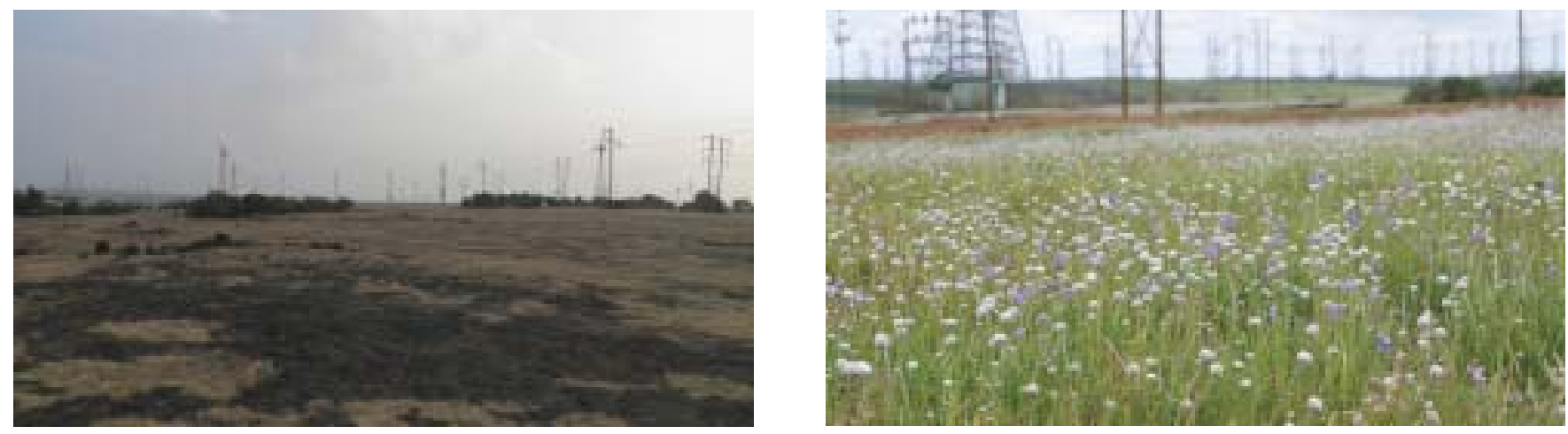

Image 3 and 4 : Extreme conditions on plateau during summer and monsoon.

Rural Development (2010) rocky plateaus feature under "Category 22" (barren rocky / stony waste areas). The anthropological definition of wasteland is the areas where woody vegetation doesn't grow. However, in nature there is no wasteland. Even these apparently barren, extensive rock patches of laterite support dense ephemeral vegetation with mass flowering in monsoon. (Image 3 and 4).

Due to high velocity winds at altitudes above $1000 \mathrm{~m}$, they were considered suitable for wind farms. The development work was also facilitated by the ease in procuring rocky plateau land, which did not have much of cultivated or residential areas.

One of the highest density windfarms in Maharashtra has been installed near Chalkewadi village of Satara dist, Maharashtra. It is one of Asia's largest windfarms with installed capacity of $210 \mathrm{MW}$, and having approximately 1000 windmills on plateau area located on the top of Northern Western Ghats ranges.

Environmental impact assessment studies are not mandatory for windfarms. Very few studies address the impact of windfarms on avifauna in India, as per Pande et al. (2013). The objective of our study was to document impacts of wind farm installations and
Field observations were taken every month on a line transect which started from wind farm at Chalkewadi, near Thoseghar, an approach from Satara and ended at diversion to Wan-kusawade. These observations are combined with various spot surveys depending upon need and area observations. Observations included :

1. Biodiversity

2. Micro-habitats like ponds

3. Alteration to habitat and its impacts

4. Area analysis - various habitats, roads, windmills, etc.

An open source tool for 'area mapping' was selected. The field observations were supported by marking of specific points using GPS and the coordinates were marked with necessary notes. These were marked on the Google Earth map. Images from 2002 were available and were compared with the present observations and images. The analysis of the maps, area calculations using Google Earth Pro and secondary data available regarding the rocky plateau habitats was used for the discussion on impacts of windfarms. It is understood that use of better aerial images and use of tools like GIS will impart more accuracy to this study. 


\section{Study area}

The study area chosen for observations and mapping is extensively spread between Chalkewadi near Thoseghar and Patan, a taluka place in Satara District. For the purpose of this paper, it is termed as the Chalkewadi-Patan Plateau. This area is part of the

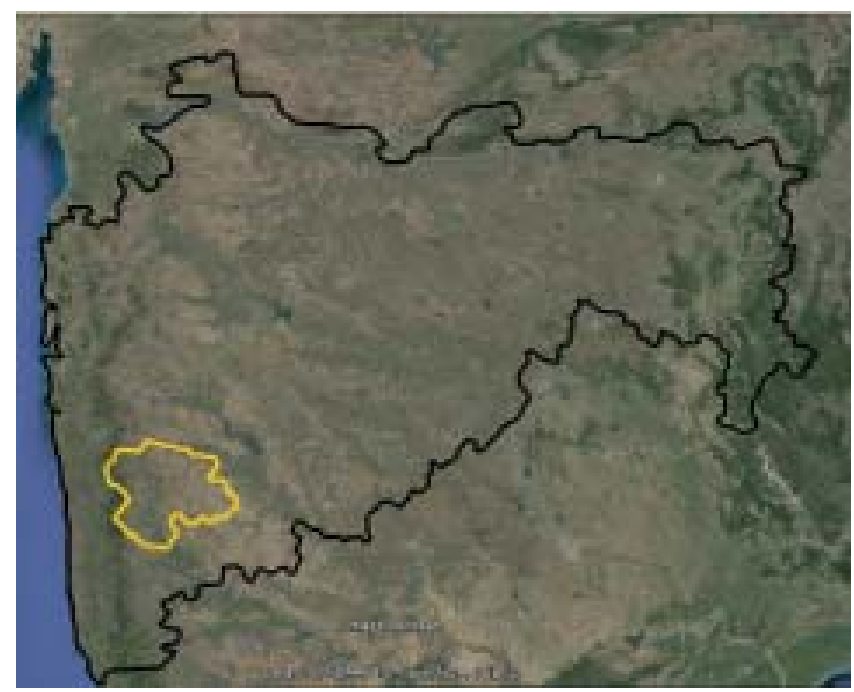

catchment of the Koyna reservoir, located to the east of reservoir, in close proximity to the Koyna Wildlife sanctuary. It also comes under the proposed buffer of Sahyadri Tiger Reserve.

Chalkewadi-Patan Plateaus are spread between $17^{0}$ $41^{\prime} 42.01^{\prime \prime} \mathrm{N}, 73^{\circ} 48^{\prime} 04.98^{\prime \prime} \mathrm{E}$ (North extremity of the plateau) and $17^{\circ} 24^{\prime} 51.38^{\prime \prime} \mathrm{N}, 73^{\circ} 50^{\prime} 47.10^{\prime \prime} \mathrm{E}$ (South

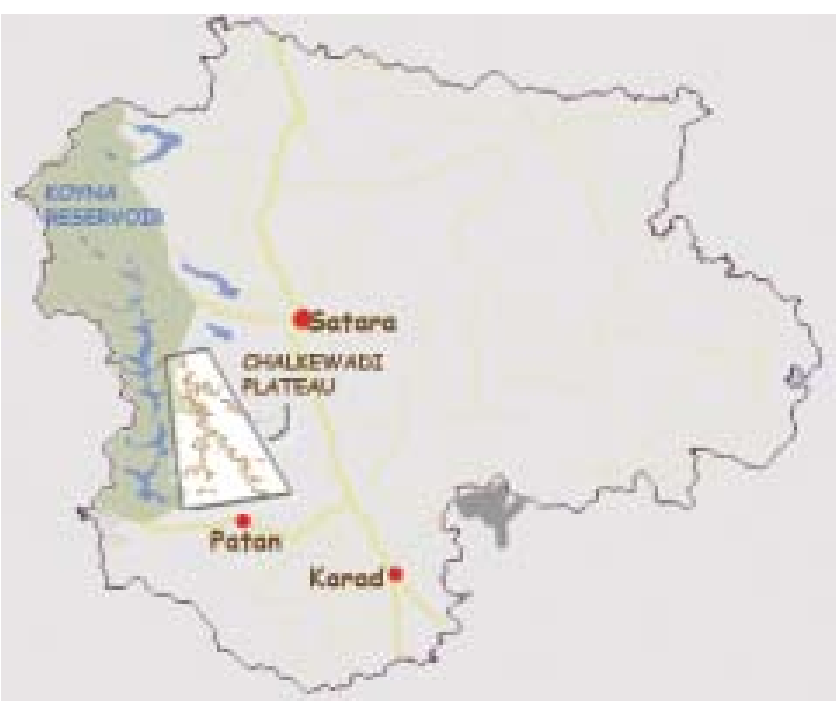

Image 5 and 6 : Map of Maharashtra showing district Satara and Map of District Satara showing location of Chalkewadi plateau complex

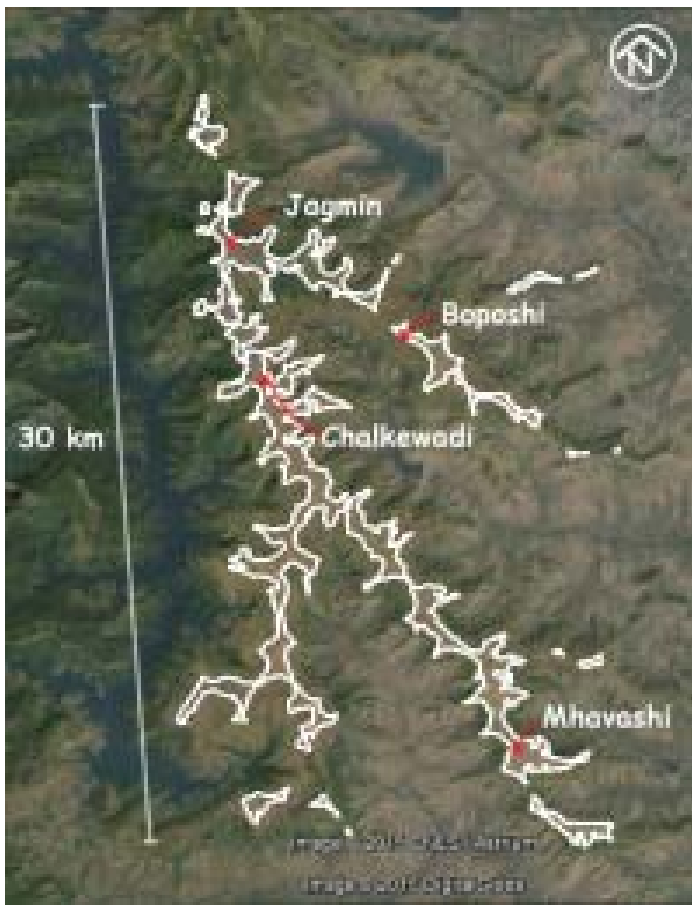

Image 7: Image showing extent of rocky plateaus of Chalkewadi - Patan complex extremity of the plateau), with average highest elevation of $1137 \mathrm{~m}$.

Being in Sahyadri, this plateau receives high rainfall. The annual rainfall of nearby Koynanagar is reported to be 4,957.3-5,666.1 $\mathrm{mm}$ (S. Nandargi and S. S. Mulye, 2012).

This plateau has a maximum width of $3.6 \mathrm{~km}$ with aerial length of $30 \mathrm{~km}$ approximately. The plateau complex consists of narrowly connected small plateaus or isolated plateaus having different names as per the villages, e.g. Sada Waghapur. It has a gradually undulating flat top with presence of gullies, streams, patches of vegetation and few depressions.

Plateau habitats can be categorized into terrestrial or aquatic microhabitats. Based on the soil depths and vegetation, terrestrial habitats can be further divided into open rocky patches, grasslands on areas having soil cover (both with ephemeral monsoon flora), shrub clusters and dense clusters of trees (Image 8). Terrestrial herbs include members of Fabaceae, Eriocaulaceae, Lentibulariaceae, and Rubiaceae.

Aquatic habitats are ephemeral pools, perennial ponds, and monsoon streams. Ephemeral pools form in shallow depressions and support aquatic flora 


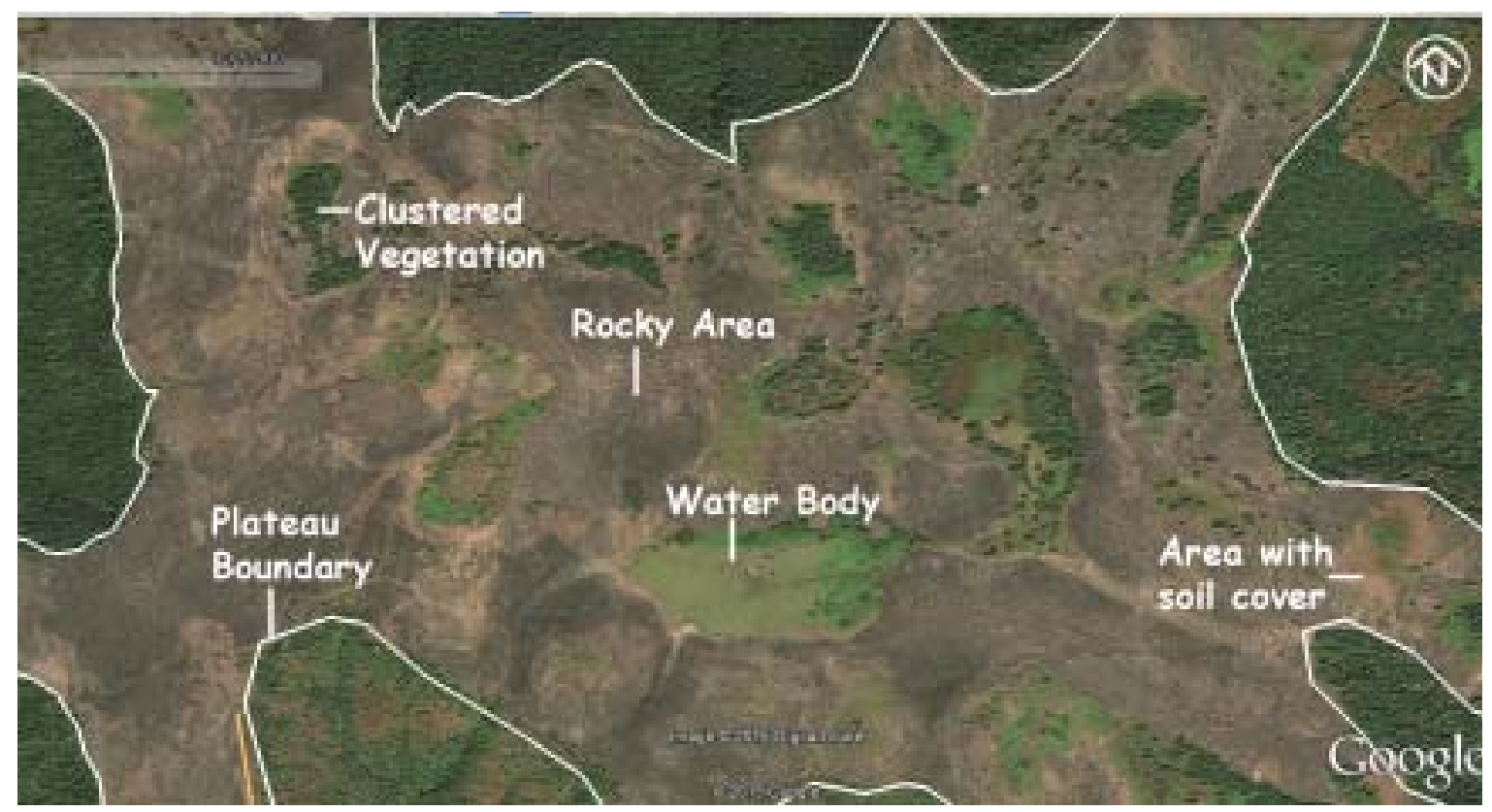

Image 8: Various habitats on rocky plateau

including Aponogeton satarensis and Eriocaulon tuberiferum (both endemic to Western Ghats). Aquatic invertebrates such as tadpole shrimps, beetles, larvae of dragonflies and damselflies are found in ephemeral pools. Fish and endemic frogs like Ncytibatrachus humayuni and Rana aurantiaca are found on the plateau.

A new species of spider, Tylorida sataraensis Kulkarni, 2014, is associated with perennial streams. In this study, ten plateaus were surveyed across northern Western Ghats. Among these sites, T. sataraensis was observed only at Chalkewadi and Kaas plateaus. Based on its current known distribution, the species would likely fall under IUCN status Critically Endangered (CR) following Criteria B1ab(iii)+ B2ab(iii) (IUCN 2012). Among the threats observed in the study area, loss of vegetation cover and removal of laterite rocks are likely to be direct threats to $T$. sataraensis. Such microhabitat degradation, if permitted to continue, could reduce the amount of shaded areas and alter the micro-strata required by the species for web construction. (Kulkarni S and Lewis T, (2015)).

The newly reported Satara gecko, (Hemidactylus satarensis) (Giri and Bauer, 2008) is also likely to be found in the study region.

The following table illustrates list of plants seen at Chalkewadi with respect to various habitats.

$\begin{array}{ll}\text { Habitat type } & \text { Flora } \\ \text { Rocky Area } & \text { Begonia crenata } \\ & \text { Crustose lichens (Parmeliace } \\ & \text { Cyanobacteria } \\ & \text { Cyanotis spp. } \\ & \text { Indigofera dalzelii } \\ & \text { Lepidagathis prostrata } \\ & \text { Neanotis spp. } \\ & \text { Nostoc spp. } \\ \text { Area with thin } & \text { Adelocaryum coelestinum } \\ \text { soil cover } & \text { Ceropegia jainii } \\ & \text { Drosera spp. } \\ & \text { Eriocaulon spp. } \\ & \text { Exacum pumilum } \\ & \text { Habenaria spp. } \\ & \text { Hedyotis stocksii } \\ & \text { Hygrophila serpyllum } \\ & \text { Impatiens balsamina } \\ & \text { Impatiens lawii } \\ & \text { Impatiens oppositifolia } \\ & \text { Indigofera dalzelli } \\ & \text { Jansenella spp. } \\ & \text { Murdannia spp. } \\ & \text { Paspalum canarae } \\ & \text { Peristylus spp. } \\ & \text { Pogostemon deccanensis } \\ & \text { Rotala spp. } \\ & \end{array}$


Senecio dalzellii

Smithia spp.

Utricularia spp.

\section{Clustered Vegetation}

\section{Water Bodies} with habitats and disturbance to the integrity of habitats may impact flora negatively.

This plateau complex is privately owned mainly by the local villagers and windfarm companies. A part of the plateau, towards the reservoir is owned by State
Forest Department. The wind farm on these plateaus was established around 2002, on privately owned lands by locals which were purchased by the company. It has been operational with more than 900 windmills and supportive infrastructure.

\section{Findings}

Field observations were started in 2006 with the aim of documenting seasonal changes in biodiversity and impacts of installation and operations of the windfarm.

Establishment of windmills is an intensive development on a plateau. It includes road laying, excavations, use of cement-concrete for piling for the windmill, poles, transformer rooms, guest houses, supportive service development, storage of oil, chemicals, movement of cranes and creating plain surfaces for them, etc. All of this has some impact on ground and thus on habitat. (Refer to image 12)

Windfarms cannot be built without large scale construction of roads. These linear roads have the following impacts :

a. Have changed the freshets and streams

b. Have created few areas with water storages

c. Road construction has led to extraction of murum-soil-rocks from surroundings

d. Dissected the habitat (refer to image 11)

e. Created habitats for herbs like Neanotis lancifolia, Senecio sp, which are indicators of degraded or changed habitats,

f. Initiated road kills (refer to image 12),

g. Increased erosional features along road.

2. Many dirt roads are in use on the plateau. Their condition deteriorates over time. Owing to this, vehicles start driving along the shoulders and then off road and stray into the open areas. This destroys the habitats along roads leading to
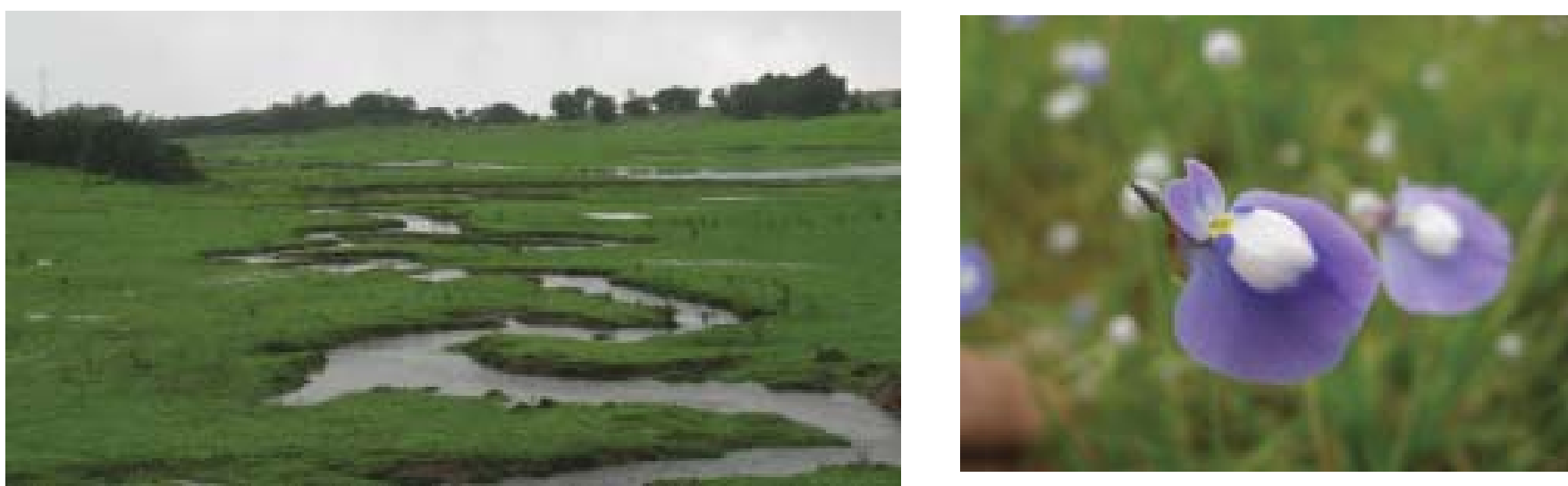

Image 9 and 10: Monsoon streams and insectivorous herb Utricularia sp. 
widening of present roads and formation of offshoots.

3. Fan-throated lizards were observed during their pre-breeding season. They were seen using supports and wires for poles, fences, white stones marked along road for courtship displays. Even the number of lizards along roads seems to be high, but this needs to be validated with detailed studies of this and similar habitats. In one visit 13 males and 14 females were observed in one transect of $1 \mathrm{~km} \times 10 \mathrm{~m}$ along road in the month of June. These lizards have the risk of getting killed by vehicular traffic.

4. The plateau is subjected to heavy downpour and periods of fog during the months of June through November. This initiates algal growth on

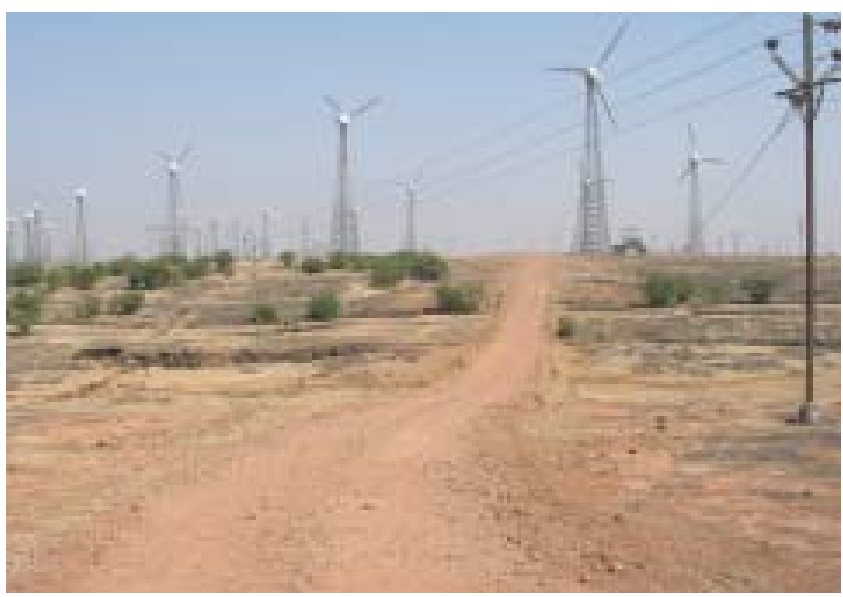

\section{Area mapping}

\section{Land Classes in a pre and post Windfarm scenario}

Area mapping was based on identifying and delineating various habitats on plateau. The following natural habitats and human-centric areas are found on a typical plateau, with or without windmills.

1. Water Bodies: This includes natural streams originating on the plateau only during the monsoon season as well as manmade or naturally formed small or large pools, which are either seasonal or perennial.

2. Area with soil cover: There are intermittent areas on the plateau that have soil cover of varying depths. Depending upon the depth, vegetation character in these areas changes. Predominant

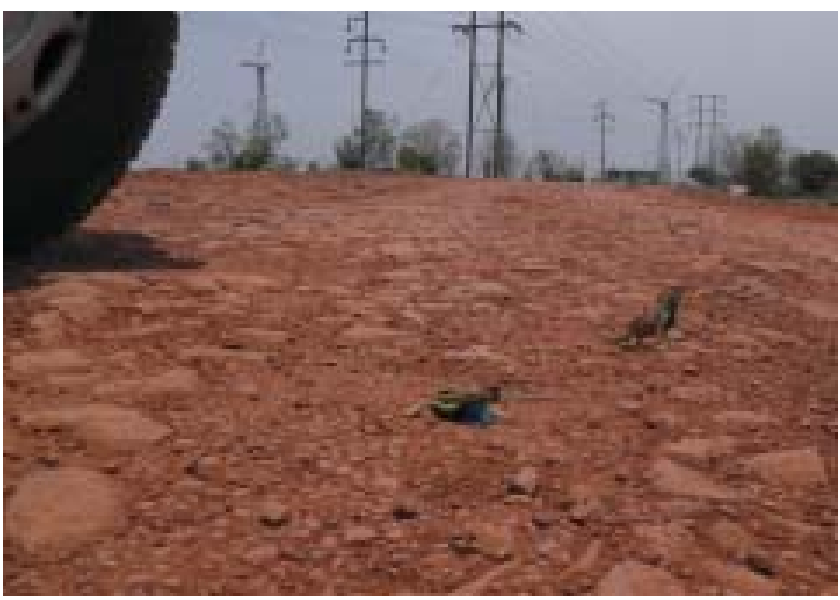

Image 11 and 12 : Roads dissecting habitats and effects on minor fauna such as fan throated lizard

windmill blades which reduces the efficiency of windmills. To overcome this, the algal layer is washed off periodically with cleaners and detergents every year. There would be a definite impact of the chemical residue on the soil, habitat and water bodies, but it has not yet been studied.

5. It was also observed that the locations where any earth moving / digging / material removal has happened in rocky areas, different floral diversity associated with loose soil flourish in next few years. Examples are road sides, trenches, subsurface pipeline works where Neanotis lancifolia can be seen which is not abundant on rocky areas otherwise.

Further studies are required on each of the above observations. vegetation in these areas is herbs and shrubs.

3. Clustered Vegetation: A continuous tree cover is almost absent on the plateau. Still there are few areas where one can find sparse or dense tree clusters, combined with shrubs.

4. Rocky Area: The areas with laterite, where specialized species of algae, grasses and herbs in rock crevices are present.

5. Human Settlements: Historically few communities have stayed on the plateau and conducted activities like rain fed farming, house construction, etc. These areas are included under settlements.

\section{Post-windfarm scenario}

Addition of windmills requires roads, supporting structures, canteens, guest houses, scrap yards, 


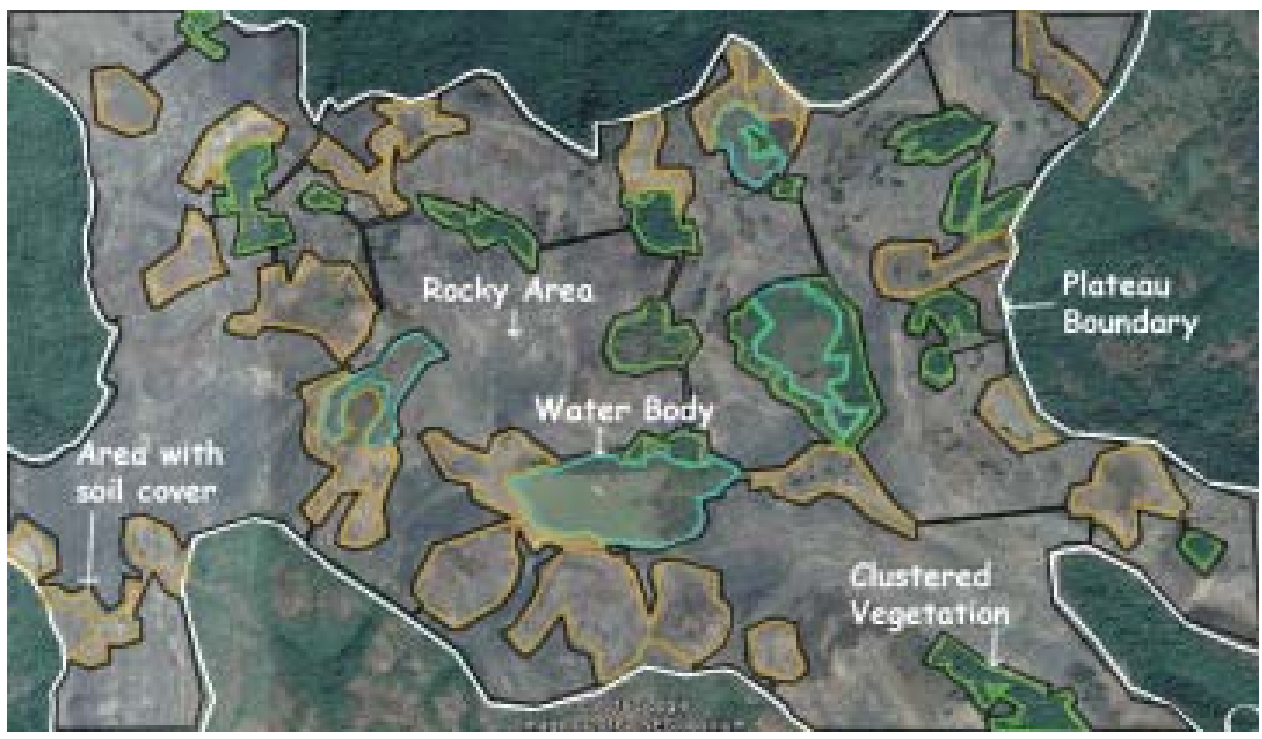

Image 13 : Various plateau habitats: indicative figure

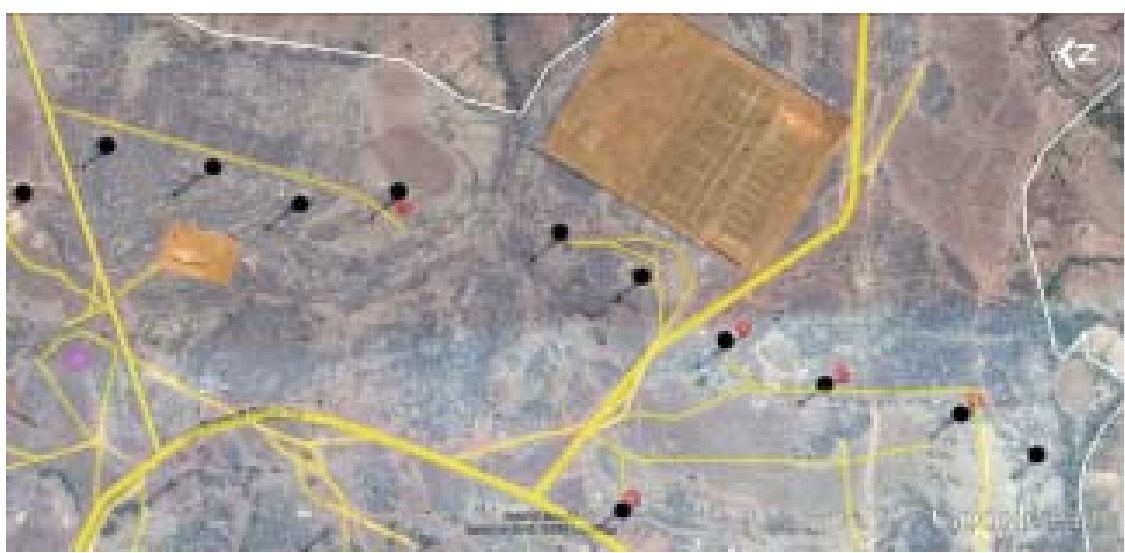

Land Use:

Windmills

- Helipad

Electric transformers

Support Structures

Roods, Sub roads and Cattie roads

Image 14 : Windmill infrastructure

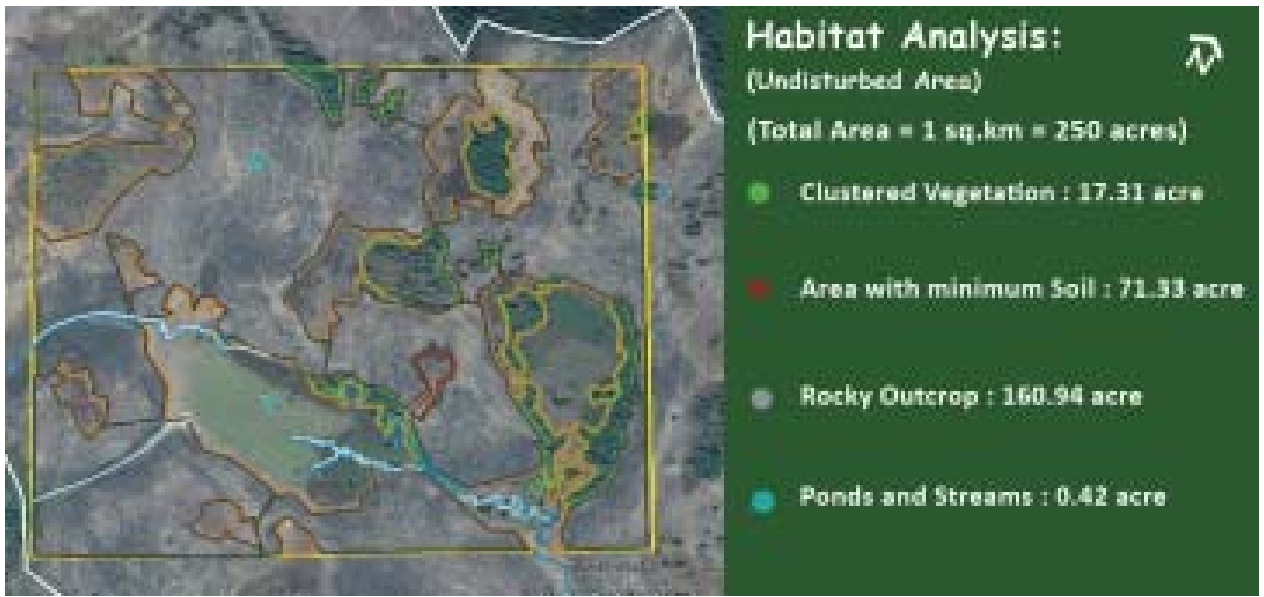

Image 15 : Habitat analysis of area where windmills are not present 
substations and such other facilities. This takes up significant portions of land.

The following section explains the mapping method used for the entire complex.

An area of $1 \mathrm{sq}$. km. was chosen from no-windmill areas and windmill affected parts to know the distribution of the original, undisturbed habitat structure vs. disturbed habitats.

Habitat Analysis of 1 sq. km. Area in no-windmill and windmill-affected regions :

No-windmill area : The area which is not affected by direct impacts of windmill. Human activities of local population like grazing, fuel wood extraction and fire continue in this patch. These activities have the effect of disturbing natural habitats. windmill activities that directly affected the natural habitats was recorded.

$1 \mathrm{sq} \mathrm{km}=250$ acres

\begin{tabular}{|c|c|c|c|}
\hline No. & $\begin{array}{l}\text { Habitat/ } \\
\text { land class }\end{array}$ & $\begin{array}{l}\text { Area } \\
\text { (in acres) }\end{array}$ & $\begin{array}{l}\text { Percentage } \\
(\%)\end{array}$ \\
\hline 1. & Area with soil cover & 91.26 & 39.92 \\
\hline & Rocky Area & 113.27 & 45.30 \\
\hline & $\begin{array}{l}\text { Water bodies } \\
\text { (streams, ponds) }\end{array}$ & 5.94 & 2.59 \\
\hline & Clustered Vegetation & 1.46 & 0.584 \\
\hline & Settlement & 22 & 8.8 \\
\hline & Area under windmills & 2.059 & 0.90 \\
\hline & Area under roads & 14.07 & 6.15 \\
\hline
\end{tabular}

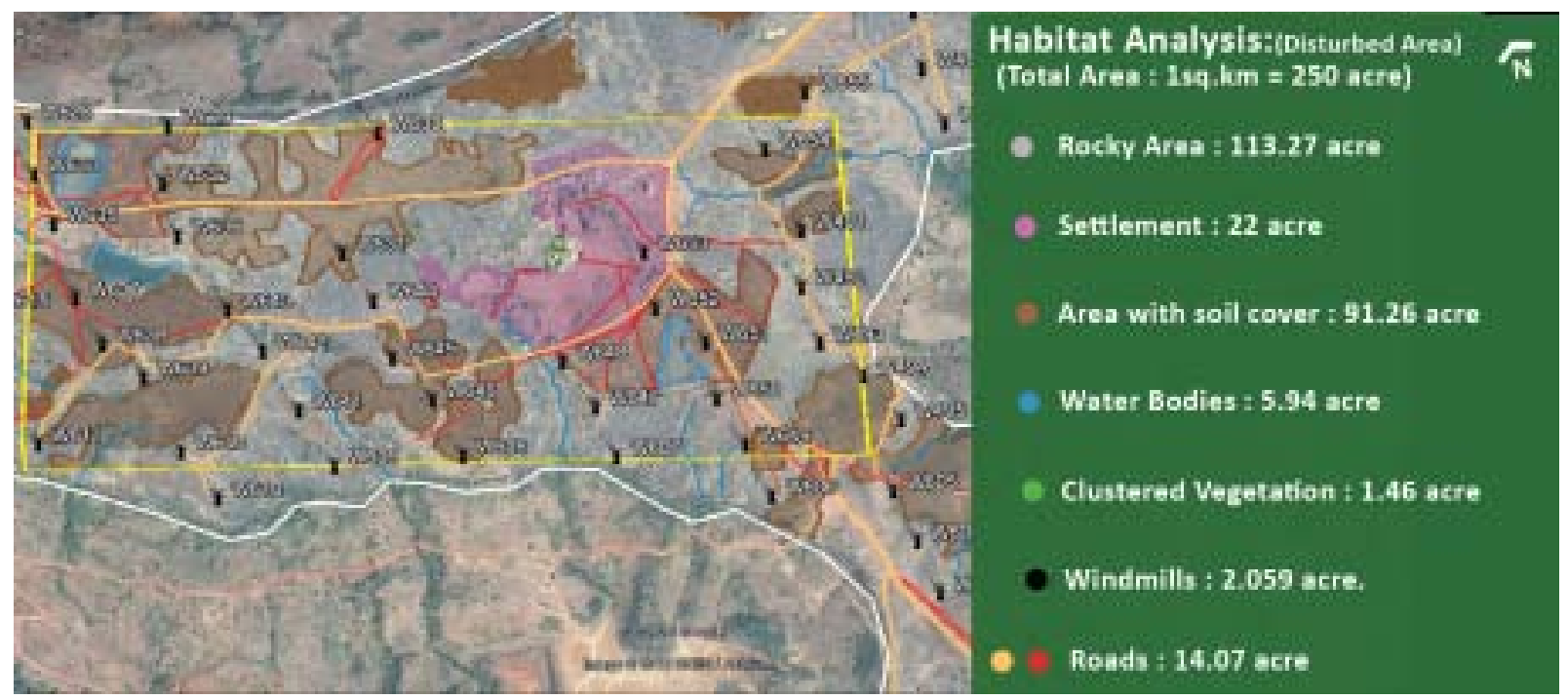

Image 16 : Disturbed area due to development of windmill

$1 \mathrm{sq} \mathrm{km}=250$ acres

$\begin{array}{llll}\text { No. } & \text { Habitat } & \begin{array}{l}\text { Area } \\ \text { (in acres) }\end{array} & \begin{array}{l}\text { Percentage } \\ (\%)\end{array} \\ 1 & \text { Clustered Vegetation } & 17.31 & 6.92 \% \\ 2 & \text { Area with soil cover } & 71.33 & 28.53 \% \\ 3 & \begin{array}{l}\text { Rocky Area } \\ 4\end{array} & 160.94 & 64.38 \% \\ \text { Water bodies } & 0.42 & 0.17 \% \\ & \text { (streams, ponds) } & & \\ & \text { Total } & 250 & 100 \%\end{array}$

Windmill-affected area: This area comes under direct influence of establishment and maintenance activities of windmill farms. Here the area covered by 


\section{Road analysis}

The roads seen on plateau are divided into 4 categories according to the measurements and utilization

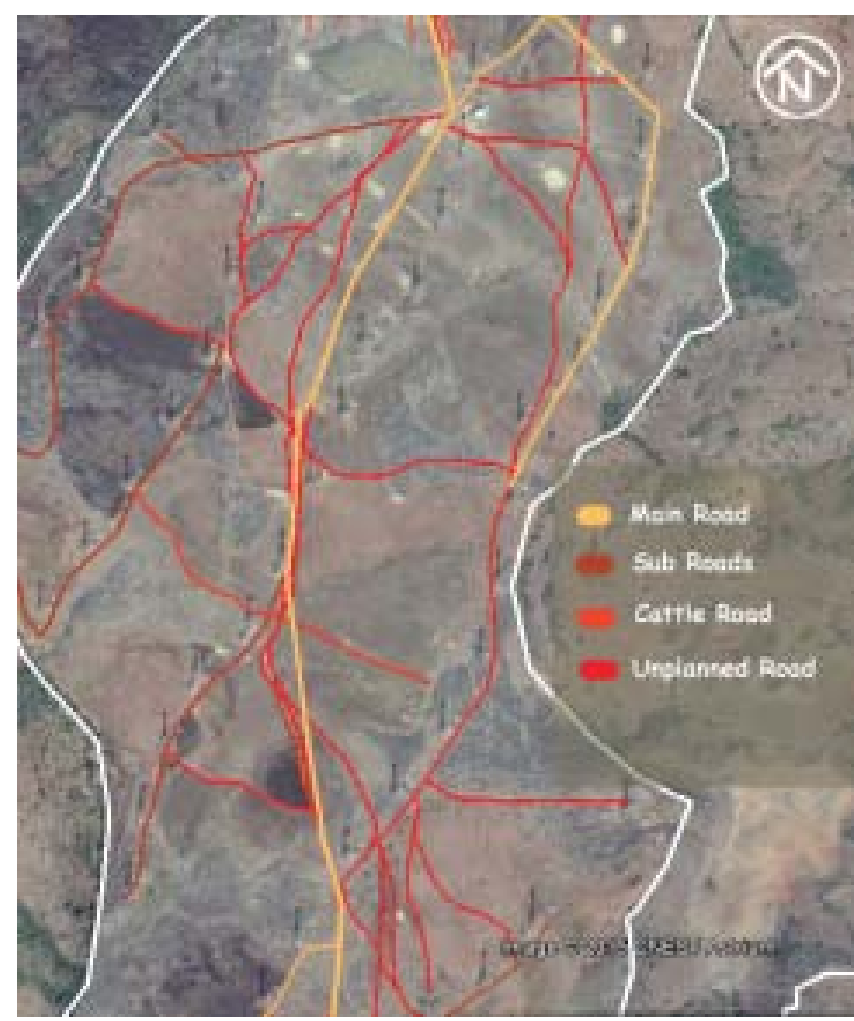

\section{Main Road:}

Length: $148.7 \mathrm{~km}$, width: $8 \mathrm{~m}$

Sub Road (Joining Main road and Windmill):

Length: $105.39 \mathrm{~km}$, width: $3.5 \mathrm{~m}$

Cattle Road:

Length: $21.38 \mathrm{~km}$, width: $1.2 \mathrm{~m}$

Unplanned (off-road) Roads:

Length: $81.47 \mathrm{~km}$, width: $3.0 \mathrm{~m}$

Image 17: showing all major types of road present on the plateau.

The typical width for each road type was measured on ground and on Google Earth and averaged for calculation purposes.

Out of these categories, the main roads and subroads to windmills are necessary, but the unplanned roads are result of bad quality of main roads. If the quality of roads is maintained properly, then these temporary roads will not develop which are of length of $82 \mathrm{~km}$.

\section{Micro-habitats dissected by roads}

Few unplanned road stretches were selected by nonrandom sampling method for analyzing which habitat it has affected. The following table shows the roads, locations and impacted habitats. 


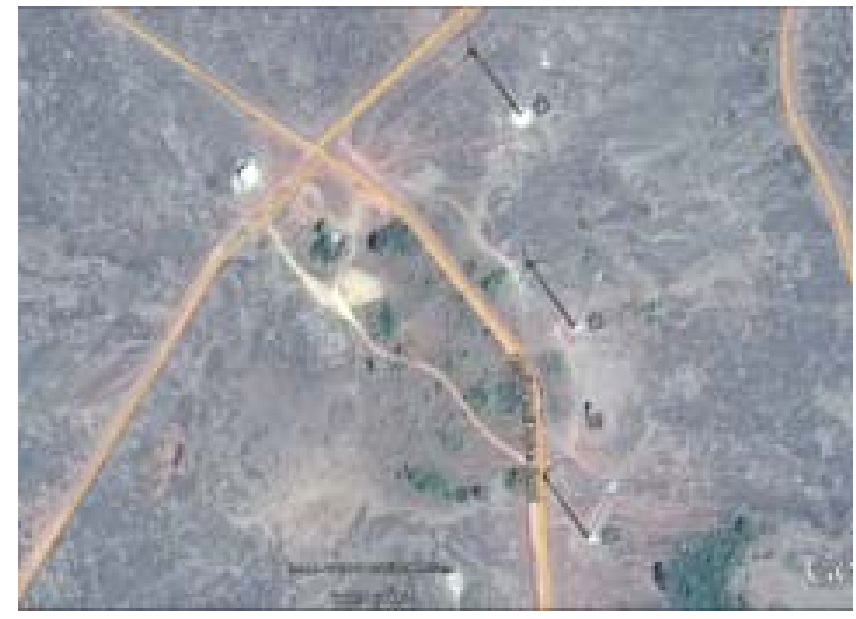

$17^{0} 34^{\prime} 50.15^{\prime \prime} \mathrm{N}, \quad 73^{0} 49^{\prime} 26.09^{\prime \prime} \mathrm{E}$

Habitats disturbed: Areas with soil, Rocky areas, Clustered vegetation

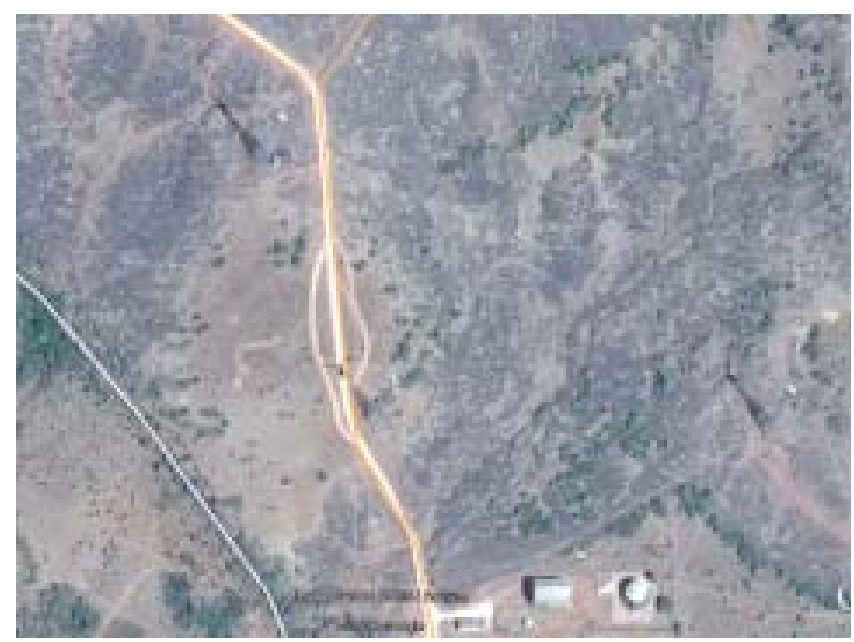

$17^{0} 32^{\prime} 26.91^{\prime \prime} \mathrm{N}, \quad 73^{0} 50^{\prime} 15.92^{\prime \prime} \mathrm{E}$

Habitats disturbed : Areas with soil, Rocky areas

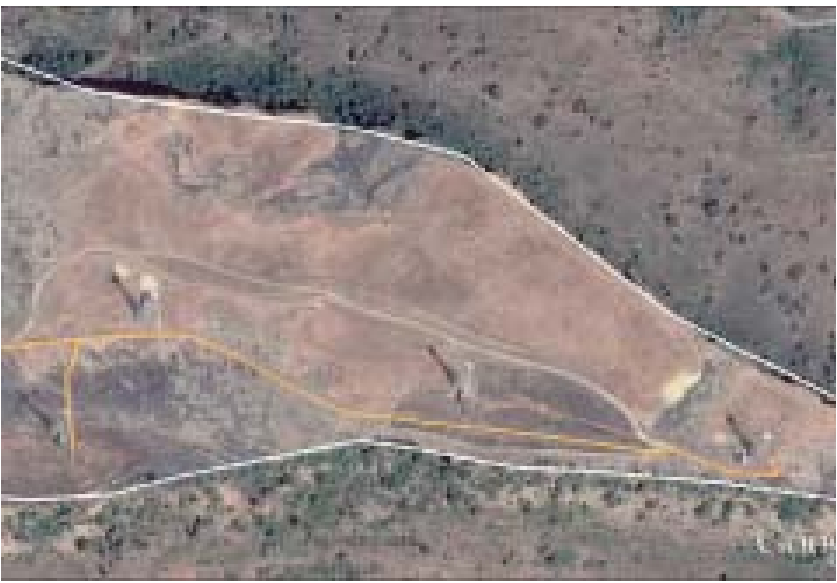

$17^{0} 33^{\prime} 44.77^{\prime \prime} \mathrm{N}, \quad 73^{0} 51^{\prime} 39.30^{\prime \prime} \mathrm{E}$

Habitats disturbed : Areas with soil, Rocky areas

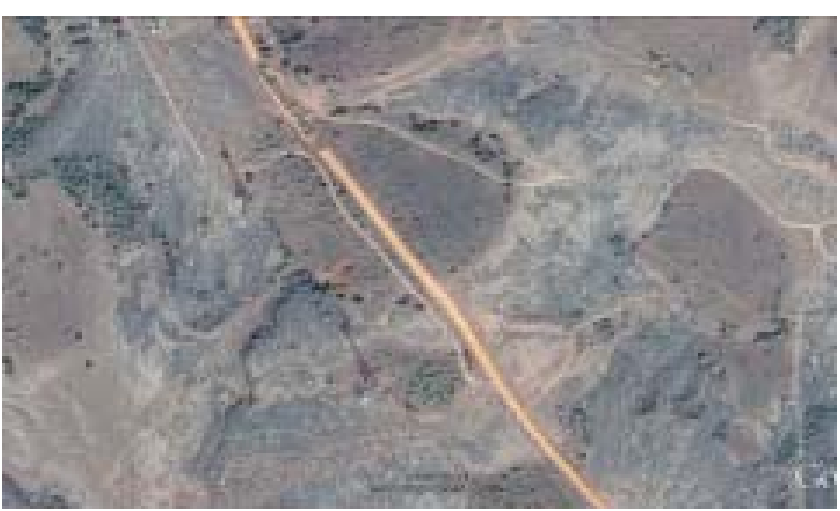

$17^{0} 32^{\prime} 09.04^{\prime \prime} \mathrm{N}, \quad 73^{0} 50^{\prime} 34.56^{\prime \prime} \mathrm{E}$

Habitats disturbed : Areas with soil, Rocky areas 


\section{Plateau Land use I Area statement}

From this mapping exercise, area calculation was done for each habitat type and land use for the plateau complex. The following tables give details of area under each type.
No Land use

1 Total area under Chalkewadi-Patan plateau complex

Area of plateau without windmills

Area of plateau with windmills

2 Habitats before windmill establishment over entire Chalkewadi-Patan plateau complex

a Rocky Area

9786.3

b Area with Soil Cover

6831.4

C Clustered Vegetation

300.7

129.2

86.5

C Windmill Structures

27.0

e Windmill Support

f Cattle Road

Direct destruction of habitats - Total

4 Road analysis

Total Area under roads

420.5

100.0

$\begin{array}{ll}\text { a } & \text { Main Roads } \\ \text { b } & \text { Sub-roads } \\ \text { c } & \text { Unplanned Road } \\ \text { d } & \text { Cattle Road }\end{array}$

a Main Roads

297.4

92.2

24.4

6.4
0.8

0.5

Note: Data analysis presented is based on the google imagery of January 2016. The numbers and area calculation may differ if more accurate methods like GIS software are used. 
From the mapping, following analysis can be made :

1. Total area under plateau is bifurcated as area with windmill farm $(70.6 \%)$ and area without windmill farms $(29.4 \%)$. The areas that do not have windmills are the plateaus which are either disconnected small plateaus or area under 'reserved forest'. The area with windmills is privately-owned lands.

2. The area with windmill establishment (12096 acres) has the related support infrastructure, percentage of area under direct disturbance is relatively low, almost $4 \%$, the remaining $96 \%$ area is indirectly affected.

4. It was observed that the road network has significant impacts on the habitat.

Image 21 shows a network of main road along with the off-roads. It is evident that due to channelization of flows of rainwater, the soil erosion on east side of the road is initiated. Being a very high rainfall area, high
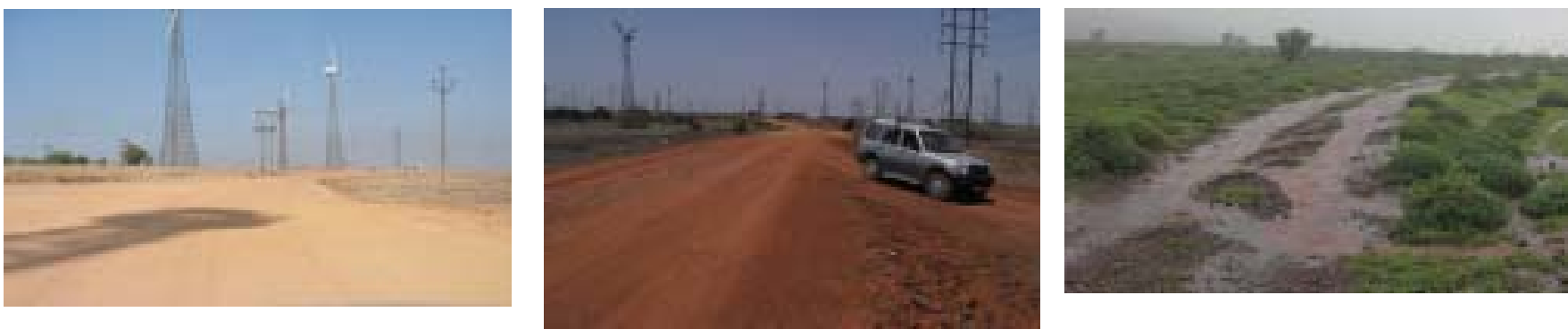

Images 18, 19 and 20 : show widening of main roads, vehicles preferring the temporary roads and effects of these temporary roads on the vegetation growth and water flows.

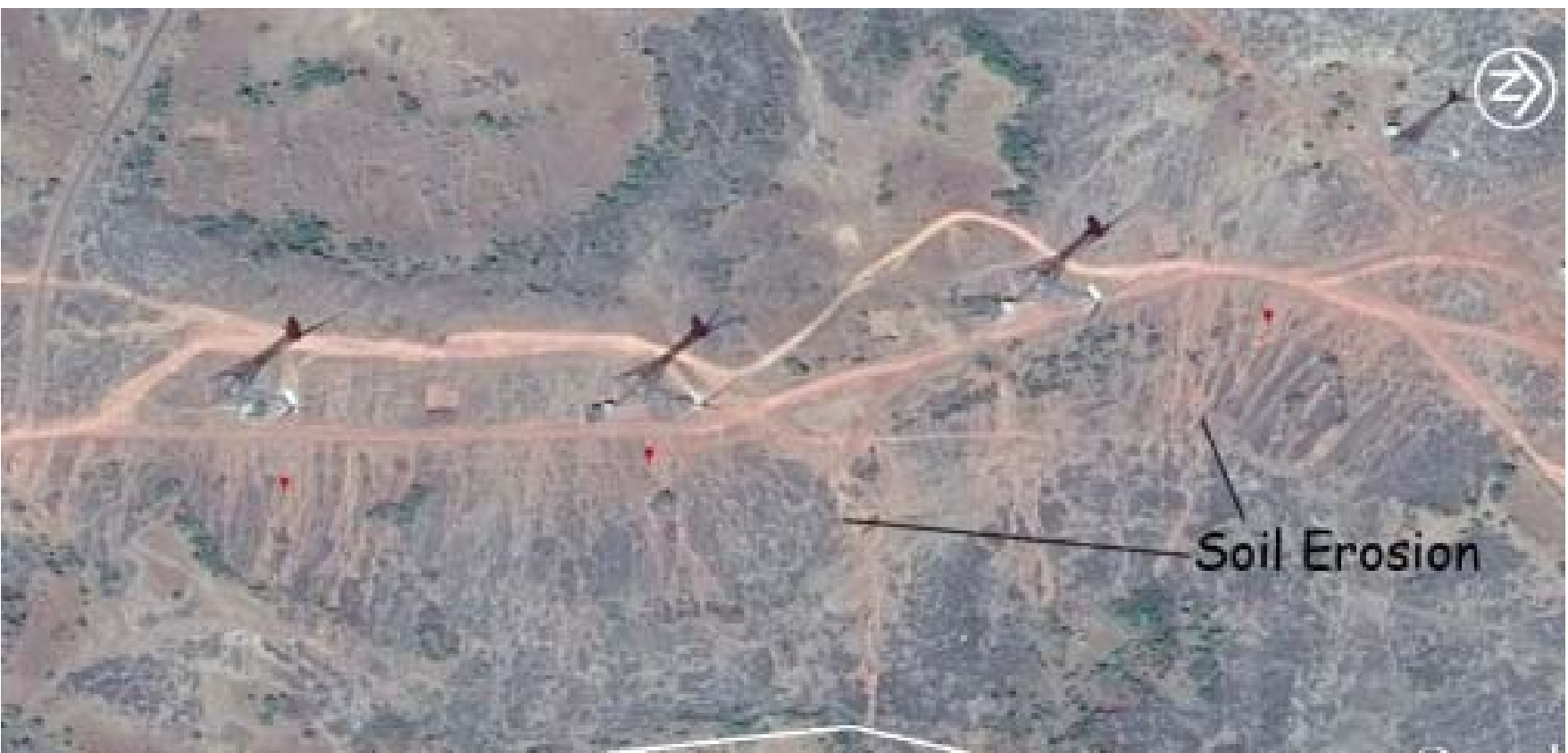

Image 21 : Soil erosion initiated due to road work

particularly roads, amounting to 515 acres where the original habitats have degraded.

3. This infrastructure is spread across the entire 12096 acres of plateau area. Even though the intensity rains and the flows thus formed tend to erode more. Eventually, changes in topography result in heavy degradation.

Another impact of roads is trampling of vegetation 
and compacting of ground. Both have serious effects on population of the ephemeral plant vegetation, ultimately affecting the food chains, overall food web, and energy and material flows in the natural ecosystem. There is an increase in number of road kills of frogs and reptiles, specifically Sarada superba which display openly during breeding seasons. Thus one major impact of roads is fragmentation of micro habitats.

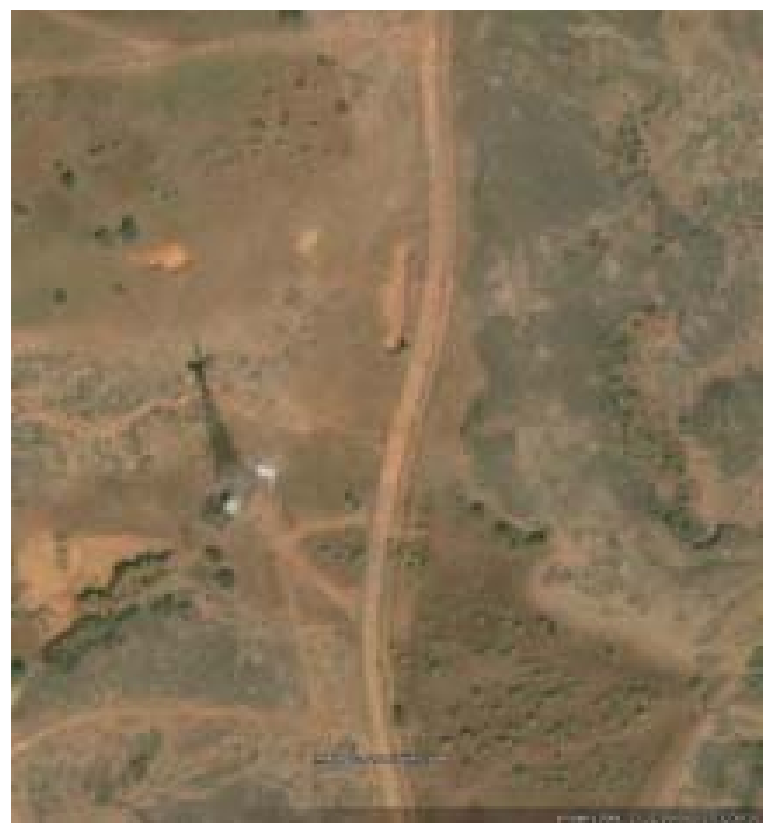

richness and diversity reduced considerably with increase in trampling intensity.

Another impact, though not documented in these specific locations is bird collisions due to windmill blades and poles. Some studies have analysed the number of birds and mammals being affected due to windfarms. One such study at a similar location in the Sahyadri region by Pande et al (2013) tries to evaluate the risks of bird collision. It estimates a collision index

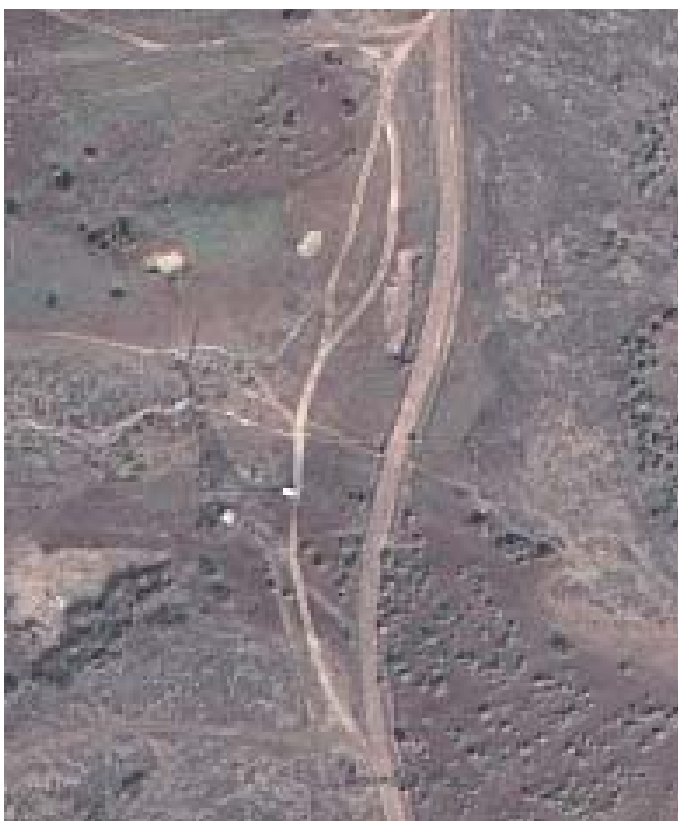

Image 22 and 23 : Multiple unplanned roads are seen in $2^{\text {nd }}$ image

Also compacting of ground directly affects percolation of rain water and recharging of the spring systems on which the entire life and economy in surrounding villages depend. So even if the current extent of land impacted is low, the gradual increase in such temporary roads will affect recharging in future.

Comparative images (22 and 23) of the same spot in Nov 2005 and Nov 2012, show appearance of multiple temporary roads along the main road, clearly indicating that as the main road's quality deteriorated (also evident from field observations), vehicles start creating new roads that are almost parallel to the main road.

\section{Discussion}

The effect of walking / vehicle plying on plateau through trampling on the seasonal vegetation has been observed on Kaas, a rocky plateau north of current study location (Agarwal, 2014). It showed that species and observes reduction in avian activity with progress of wind farm installation. It states that despite the small footprint of area covered by an individual wind turbine, the associated infrastructure development causes wider habitat modification and destruction resulting in a displacement of birds. The annual average collision rate was 1.9 birds per turbine.

Bird collisions with wind blades and installations can cause irreversible damages to their populations and food chains. So, such establishments could be high-risk areas for avifauna.

The high number of fan throated lizards (Sarada superba) displaying boldly on this plateau in areas devoid of any vegetation also indicates lack of their predators which would be raptors. The network of windmills, poles, overhead wires and changes to local wind flows due to sweeping windmill blades may be responsible for this.

The operation and maintenance of wind farms 
involves large amount of oil which is stored on site and prone to occasional spillage and leakage. Moreover, there are cleansing agents required for maintenance and the vehicles introduce emissions in the atmosphere. The collective effect of all these elements may be to pose significant threat to sensitive biodiversity, especially those in ephemeral pools in monsoon, e.g. shrimps.

These are few of the impacts locally observed and mapped, and similar impacts can be envisaged for other plateaus in Sahyadri having wind farms or proposed for wind farms.

There are also examples where forest was cut open for providing road access to establish windmill farms, creating greater impact on surrounding area. Image 24 shows a windmill installed in vegetated patch near Gothane, even though enough area is available in open habitat for installation. In image 25 it can be seen that an access road is created through dense forested patch in Padharwadi for catering to a very small number of windmills. It will be worth computing the cost-benefit of such actions against the long-term cost of ecological

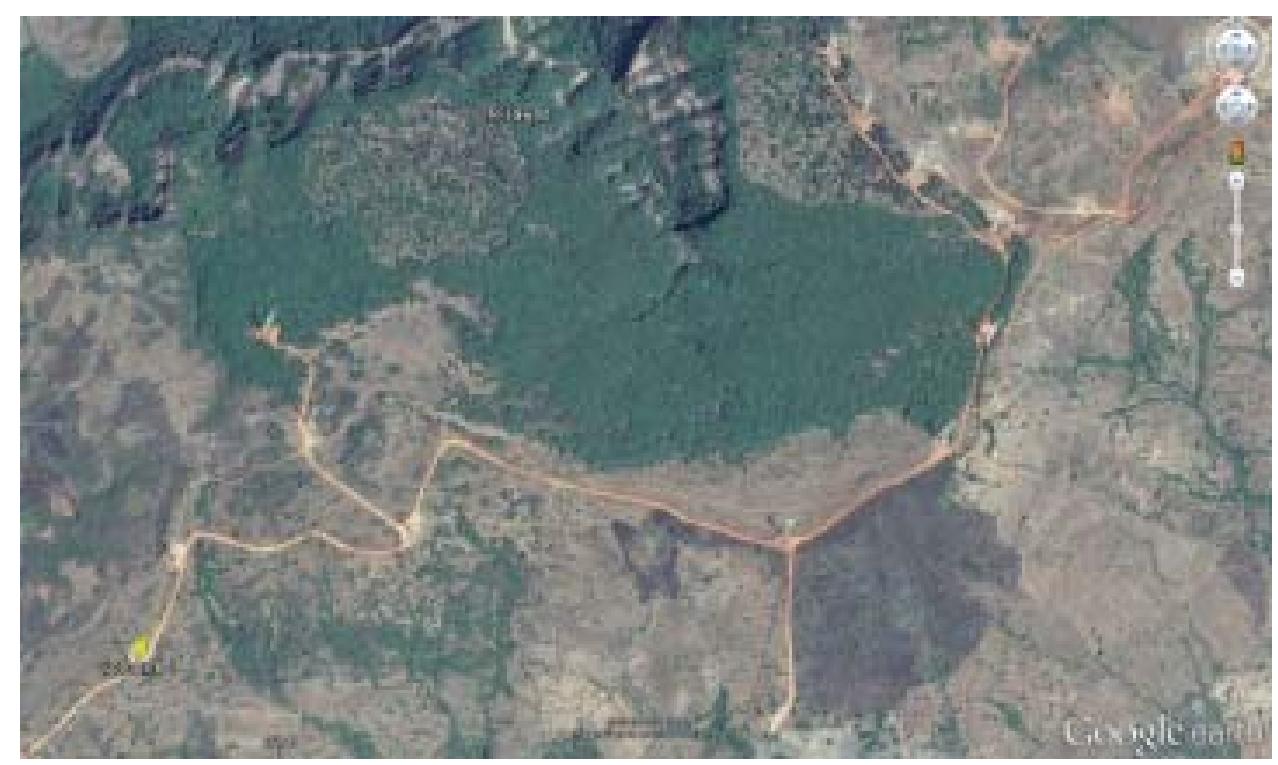

Image 24 : Area near Gothane showing few windmills are established by clearing the forest

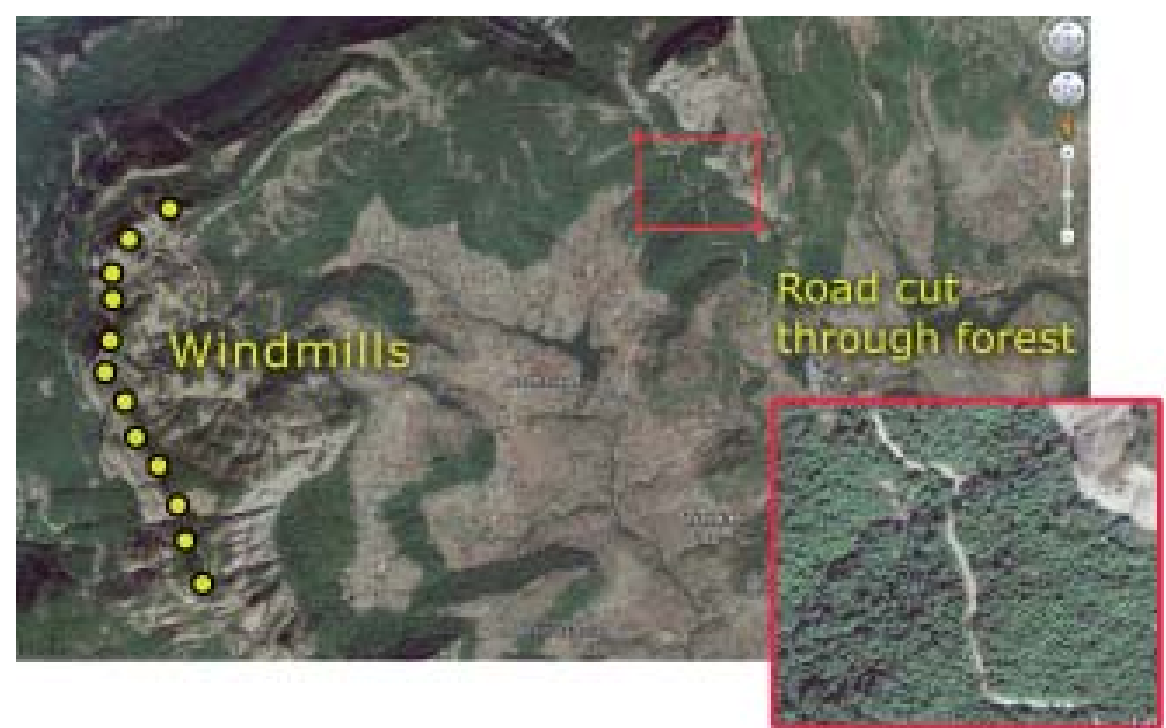

Image 25 : Windmills established at Padharwadi near Bhimashankar showing road cutting through dense forest cover to cater to a very small number of windmills 
services provided by the forests in Sahyadri.

The society is largely unaware of these environmental impacts of windfarms. Wind energy is considered to be a clean energy which can reduce fossil fuel use and related pollution. Researchers have studied the efficiency of windfarms with respect to their impacts on environment. Rosenbloom (2006) shows that wind power does not meet expected energy claims, however it has significant impacts on environment and neighbouring human settlements. Nulkar (2013) reports that in India windmills produce power on an average about $20 \%$ of their installed capacity, mainly due to intermittent winds. Mearns (2014) estimates the global wind power load factor to be $22.7 \%$, while for India it is $19.9 \%$. Using these studies, the actual electricity produced in the Chalkewadi windfarm complex could be as low as 1,008 MWH against the installed capacity of 5,040 $\mathrm{MWH}$.

Example of existing roads: Total length of roads in the image (excluding the cattle road, i.e. the one shown in orange colour) is $8.27 \mathrm{~km}$. Refer to image 26.

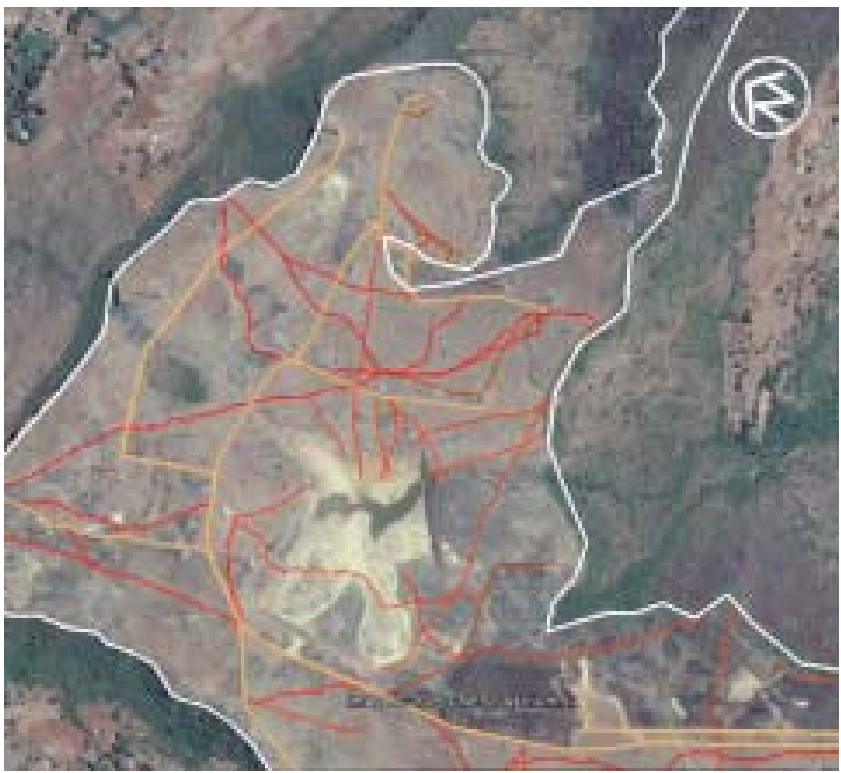

Image 26

Researchers conclude that windmills cannot be justified on the basis of 'installed capacity'. The other indirect impacts like use of fossil fuel during the process of manufacturing-installation-running, the pollution caused during manufacturing, and impact on land during installation and running of wind farm are much higher than otherwise understood, putting a question mark on this "green" energy.

\section{Recommendations}

The developments in these sensitive habitats are growing at a very fast rate. Thus it is now important to have an integrated plan that will take into consideration how habitats can remain intact. It is necessary for such an integrated plan to demonstrate that it can achieve sustenance of ecosystem services, protect biodiversity, and benefit local communities.

Below we provide a hypothetical example of how better road planning can reduce environmental impact and habitat disturbance. The location is near Jambhekar wadi.

The integrated plan should include the following measures :

1. High priority should be given to an optimallydesigned road network that helps maintenance of

If the roads are planned and constructed properly, total length of road in would be $4.47 \mathrm{~km}$. This will have less impact or disturbance to the overall habitats. Refer to image 27.

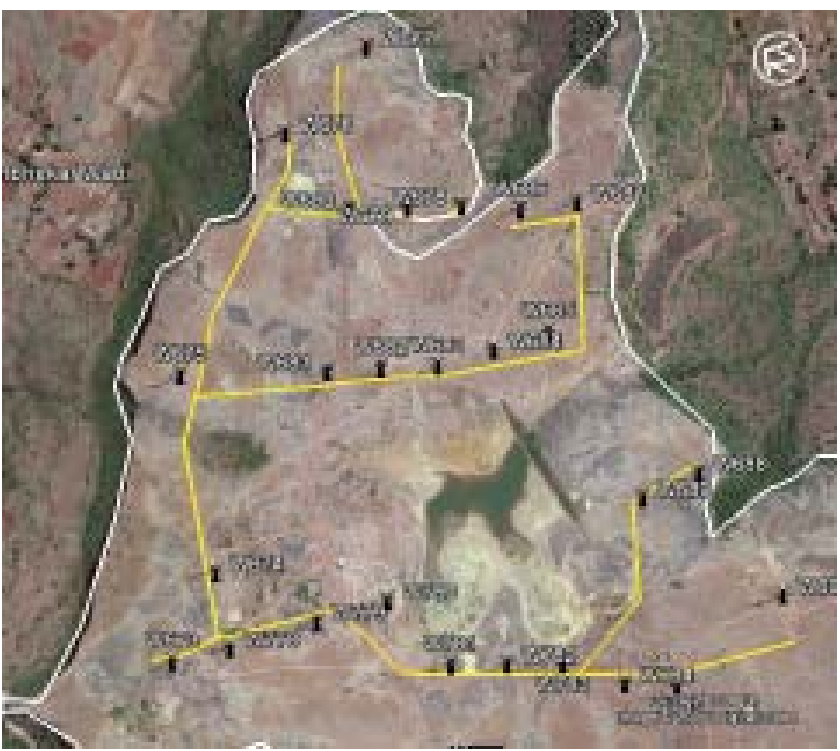

Image 27

the facility, yet minimizes ecological disturbance. It is recommended to develop roads with optimum lengths without any duplication or inefficiency, and with proper finished surfaces.

2. All temporary roads must be closed and their surfaces should be restored naturally to seamlessly merge into original habitats. 
3. Areas that are not being used directly for any of the infrastructure activity but are in possession with the windmill companies should be reserved as 'conservation areas'.

4. Long-term protection to such 'conservation areas' from windmill farm related activity should be ensured and contractually required.

5. Identify, design and implement waste management systems. It is seen that wind farm staff, villagers and tourists are littering these areas with disposable plastics, EPS (expanded polystyrene), etc. Even the liquid waste created at facilities like canteen or guest houses must be treated properly. Stricter waste management guidelines should be provided by local authorities, with penalties for violation.

6. A few seasonal ponds could be created using natural locations suitable for storing water.

7. Use of oils, diesel, tar etc should be carefully monitored. Any kind of spilling or leakage on natural habitats should be avoided and be a cause of penalties.

8. The cleaning agents used for washing windmill components should not contain toxic chemicals or mechanical cleaning should be preferred. The state's pollution control board should provide guidelines related to cleaning and what kind of cleaners are permitted.

9. Training and awareness for the windfarm management team is necessary to implement the above recommendations. Such training or awareness sessions will be required for all management levels and ground working personnel.

10. Windfarm operators, whether public companies or private individuals or companies, should be required to publish an Environmental Compliance and Sustainability Report every year providing details of their compliance and the measures they have undertaken to ensure sustainability.

11. An 'Environmental Monitoring Authority for Windfarms' should be constituted by the state government with representation of environmental experts from NGOs. This authority should have the rights to inspect windfarms at periodic times to monitor environmental compliance and report violations and other observations to the government.

Implementing such measures should be the primary responsibility of windmill companies and it should be integrated in planning, installation and operations.

Along with this, it is necessary to have changes to the policy framework to achieve clarity on how we intend to protect the remaining miniscule percentage of forests. EIA studies for wind farms should have integrated ecological management plans.

\section{Conclusion}

From this exercise of area mapping, it is seen that the most disturbing factor is road development. Even though the length of roads necessary to achieve development is approx $254 \mathrm{~km}$, its impacts are spread over entire area.

The $82 \mathrm{~km}$ of unplanned roads in Chalkewadi could be certainly avoided or reduced if roads were designed and executed optimally.

We should reconsider whether such modern development on fragile plateaus is necessary. It is necessary to evaluate the economic gain from windmills against the loss of biodiversity and ecosystem services of these plateaus.

It is necessary to initialize practices that integrate ecological and environmental sustainability considerations in windfarm projects and start implementing them immediately on ground. For the plateaus with existing windfarms it is feasible to integrate such conservation practices. In fact habitat development and improvement of natural processes by soil and water conservation measures can become a CSR activity of windmill companies.

Considering the long term impact of such projects on the natural capital on which the human race depends, it is necessary to question our lifestyle and developmental patterns that feed our increasing demand for electricity.

There is scope for further study in various aspects of habitats and biodiversity, ecosystem stress, and alteration in ecosystem services offered by the specialized habitats like rocky plateaus caused by windfarms.

\section{References}

Agarwal, P. (2014). Effect of Tourism on Kaas Plateau. http://www.rufford.org/rsg/projects / prerna_agarwal

Bhattarai, U., Tetali, P., and Kelso, S. (2012). Contributions of vulnerable hydrogeomorphic habitats to endemic plant diversity on the Kas Plateau, Western Ghats. Springer Plus, 1(1), 25.

Buono, J., Thomas, R. (2013) 'Natural Springs in the Western Ghats: A Vital Resource Under Threat: Overview, Best Practices and Policy Recommendations for Ensuring Biodiversity and Sustainable Drinking Water'. Grampari. [Online]. Available at: https://www.researchgate.net/ 
publication/236592267

Chauhan, D. , S. Agarwal, M. K. Suman (2013). Wind power scenario in India - A review, International Journal of Scientific and Research Publications, Volume 3, Issue 9, September 2013 ISSN 2250-3153.

Mearns, E. ( May 2014). The efficiency of wind power. http:/ / euanmearns.com/the-efficiency-of-windpower/

Giri, V. B. and Bauer, A. M. (2008). A new grounddwelling Hemidactylus (Squamata: Gekkonidae) from Maharashtra, with a key to the Hemidactylus of India. Zootaxa, 1700, 21-34.

Halkema, J. A. (n.d.). Wind Energy: Facts and Fiction A half truth is a whole lie.

India Wind Energy Outlook | 2012, by Global Wind Energy Council, World Institute of Sustainable Energy and Indian Wind Turbine Manufacturing Association.

Jaber, S. (July 2013). Environmental Impacts of Wind Energy. Journal of Clean Energy Technologies, Vol. 1 , No. 3.

Lekhak, M. M., and Yadav, S. R. (2012). Herbaceous vegetation of threatened high altitude lateritic plateau ecosystems of Western Ghats, southwestern Maharashtra, India. Rheedea, 22(1), 39-61.

Nulkar, G. (Dec 2013). The truth about windmills, Journal of Ecological Society, Vol 25.

Pande, Satish, Anand Padhye, Pramod Deshpande, Aditya Ponkshe, Pranav Pandit, Amit Pawashe, Shivkumar Pednekar, and Rohan Pandit. "CEPF Western Ghats Special Series : Avian collision threat assessment at Bhambarwadi Wind Farm Plateau in northern Western Ghats, India." Journal of
Threatened Taxa 5, no. 1 (2013) : 3504-3515.

Price, T. J. (May 2005). “James Blyth - Britain's First Modern Wind Power Engineer". Wind Engineering 29 (3) : 191-200.

Rosenbloom, E. (2006). A problem with wind power. Linked table "Size Specifications of Common Industrial Wind Turbines." http:/ / www.aweo.org/ windmodels.html (accessed September 12, 2015).

Watve (2013). Status review of Rocky plateaus in the northern Western Ghats and Konkan region of Maharashtra, India with recommendations for conservation and management. Journal of Threatened Taxa 5(5) : 3935-3962; doi : 10.11609/ JoTT.03372.3935-62.

Indian Wind Atlas (2010) by the Center for Wind Energy Technology (C-WET), mnre.gov.in/filemanager / UserFiles / Presentations.../ Gomathinaygam.pdf

Wastelands Atlas of India by the National Remote Sensing Centre and Ministry of Rural Development (2010), http://www.dolr.nic.in/wasteland2010/ maharastra.pdf

Kulkarni S, Lewis T (2015) Description of male Tylorida sataraensis Kulkarni, 2014 (Araneae, Tetragnathidae) with notes on habits and conservation status. Biodiversity Data Journal 3 : e4451. doi : 10.3897/BDJ.3.e4451

S. Nandargi and S. S. Mulye, 2012, Relationships between Rainy Days, Mean Daily Intensity, and Seasonal Rainfall over the Koyna Catchment during 1961-2005, The Scientific World Journal Volume 2012, Article ID 894313, 10 pages?, doi : 10.1100/ 2012/894313 